\title{
Research on laws of the formation of gas channels of the deep mining space
}

\author{
Chengwen Zhang \\ School of Resource and Safety Engineering \\ China University of Mining and Technology \\ Beijing, China \\ 785484010@qq.com
}

\section{Xiangyang Tian}

School of Resource and Safety Engineering China University of Mining and Technology

Beijing, China

1047916649@qq.com

\author{
Xiaoliang $\mathrm{Hu}$ \\ School of Resource and Safety Engineering \\ China University of Mining and Technology \\ Beijing, China \\ 1342944957@qq.com
}

\begin{abstract}
Taking 2-1 coal seam of Zhao GU second mine of Henan Coal Mine Group as the background, the article analyzed the relationship between stress of deep mining coal and rock mass and permeability, and studied the relationship between oriented flow channels namely the Gas Channels of deep mining coal and rock mass and permeability and revealed laws of the formation of the Gas Channels of the deep space mining. The research results are as follows: (1) under the impact of mining, the stress of space mining redistributes and the inner of the coal and rock mass emerges the phenomenon that cracks expanse and rupture. The channel forming at this time, in which gas flows and diffuses, is called the Gas Channel. (2) Fit out curves about stress of mining coal and rock mass and permeability in different coal and rock mass states. (3) Get the relationship between maximal and minimum permeability and distance that working face has advanced and obtain the position of permeability mutation point above the gob. (4) Gain that the permeability is related to the degree of coal and rock mass's cracks development. However, it is essentially related to stress acting on mining coal and rock mass.
\end{abstract}

Keywords-deep; the Gas Channels; mining coal and rock mass; stress; permeability

\section{INTRODUCTION}

Chinese mines are generally high gas coal mine. In the country gas accidents, especially in the south with more complex coal seam conditions, occur frequently ${ }^{[1-5]}$. One of the reasons is that most of our country coal seams' permeability is lower than $1 \mathrm{mD}$ which is a huge challenge for coal bed methane exploration and coal mine production safety ${ }^{[6-7]}$. However, how to improve the coal seams' permeability and to describe reasonably the variation of gas permeability of stope is yet a problem of mining needing to be urgently solved. At present, our country analyzes and studies permeability in main terms of cracks and porosity, etc. but hardly in term of the stress direction ${ }^{[8-10]}$.

\author{
Yi Bai \\ School of Resource and Safety Engineering \\ China University of Mining and Technology \\ Beijing, China \\ 825015341@qq.com
}

\section{THE RELATIONSHIP BETWEEN GAS CHANNEL AND PERMEABILITY}

In the coal and rock mass, gas migration is affected by the nature of coal and rock mass, methane gas, and ground stress. The three interacts, influences and restricts with each other. The influence of ground stress will make the coal and rock mass permeability greatly reduced while the existence of gas pressure will react to the stress to certain degree. Therefore, the gas permeability is a performance under the three simultaneously action, the physical mechanics properties of coal and rock mass, gas pressure and ground stress.

For the original geological environment with the high gas content, great depth and low permeability, when the stope working face advance, original stress will redistribute regularity. From the original stress band, coal and rock mass began to appear the phenomenon of stress concentration as coal and rock mass's fracture and permeability also began a series of changes. When the coal mass under the effect of mining is unloaded, the inner partial cracks form, namely forming a gas channel. At the same time, gas migrates along the gas channel and gas pressure drops and the permeability in coal and rock mass sharply increase. Gas fluid generates power to flow at a highly speed because of a gas stress and then a large amount of gas discharges.

\section{STRESS OF MINING COAL AND ROCK MASS AND PERMEABILITY EVOLUTION CURVE}

\section{A. Anfluence of mining abutment pressure on the permeability coefficient of coal and rock}

The most significant and sensitive influence factor on coefficient of permeability of coal seam is abutment pressure.Stress of mining field will be affected by mining distribution and showed certain regularity. In the original rock stress area, coal and rock mass permeability has been stable at a fixed value, also is the initial permeability. As to the working face moving closer, support pressure increases gradually, until the front of the working face, the pressure rise to the 
extreme value. Fracture closure state of coal and rock internal also reached the limit, then permeability down to the lowest leval. From the point of stress concentration to the working face location area, stress will decrease greatly, coal seam pressure releasing, cracks beganing to expand and transfix, and seepage channel rise remarkably, permeability also increase obviously.

B. The distribution of coal seam overburden stress and permeability
In numerous factors, coal and rock mass permeability plays a role which can not be ignored on coal rock and gas which coupled system stability. And under the action of external force, development process of the cracks and play a controlling role on seepage of gas. So, the research the relation between coal and rock mass fracture occurrence and development process and permeability, The changing law of the research on permeability and its evolvement rule of coal and gas coupling is of great value

TABLE I. THE TREND OF FRACTURE STRESS AND PERMEABILITY IN DIFFERENT STATES

\begin{tabular}{cccccc}
\hline & The original state & The compaction state & $\begin{array}{c}\text { The diffusion } \\
\text { condition }\end{array}$ & Restore state & The original state \\
\hline Fracture & $\rightarrow$ & $\searrow$ & $\nearrow$ & $\searrow$ & $\rightarrow$ \\
Stress & $\rightarrow$ & $\nearrow$ & $\searrow$ & $\nearrow$ & $\rightarrow$ \\
Permeability & $\rightarrow$ & $\searrow$ & $\nearrow$ & $\searrow$ \\
\hline
\end{tabular}

From the table what can be concluded is that along $\mathrm{w}$ ith the advancing process of the working face, the coal a nd rock fracture and permeability of about the same, and both with stress in the opposite direction. Due to the cha nges of stress on permeability has a great influence, so th e use of mining abutment pressure caused by the movem ent rule of surrounding rock, the relationship between pe rmeability coefficient and stress in coal and rock, can be a good guide gas extraction of coal and rock, in the coal and gas in mining plays an important role. Therefore fin ding out of coal and rock mass stress and seepage charac teristic curve equation is very important.

1) The original state stress and Infiltration feature analysis.

In the original rock stress area, due to the presence of stress stability, crack is stable at a certain value; the permeability will keep the value in the initial $\mathrm{K} 0$ state.

2) The compaction state of elastic model stress-infiltration feature analysis.

After the coal seam excavation, with the distribution of the abutment pressure, coal and rock permeability changing, gas discharge, gas pressure in coal seam of the corresponding change of coal and rock mass and will due to the effective stress changing. This will cause the coal deformation, change the pore structure of coal seam, and then use the coal seam permeability change. Coal seam belongs to low porosity and low permeability, unconventional reservoir; in the process of exploitation of permeability reduce speedily. The results show that coal specimens containing gas stress and permeability is negative index relationship before the effective volume peak. At the peak point, the effective volume should remain exponential relationship between stress and permeability coefficient, but changed, is different whit before peak.

The formula is the effective volume stress and permeability curves before the peak, in which the permeability and the effective volume stress is negative index relationship. That is:

$$
k=a k_{0} \exp ^{(-b \sigma)}
$$

Type $\mathrm{K} 0$ is the initial permeability, $\mathrm{mD}$; $\mathrm{a}, \mathrm{B}$ as the material parameters.

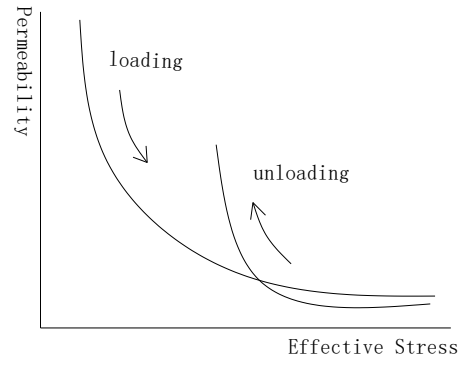

Figure 1. The relation between permeability k1 and effective stress of elastic model

In the course of coal mining, mining coal is all after loading and unloading process. Unloading, permeability evolved according to figure path, forming the inverse process of loading process, showing that the fracture, pore in the sample are not changed, nor emergence of a new fracture and coal occurs only elastic deformation, which should belong to the property elastomer material completely has the elasticity and belongs to the permeability model.

3) The diffusion state plasticity model stressseepage forces feature analysis

When the plastic damage occurring after fracture of coal body, Coal (including matrix and fracture) during unloading stress and strain are still in elastic category, the permeability law of the unloading path II permeability can be described using the loading path I . But the plastic damage makes the coal permeability compared to the loss a part. Introduce a permeability damage factor as the permeability of modified Dk. That is,

$$
k_{D}=D_{k} k_{L}
$$

In the formula, $k_{D}, k_{L}$ respectively, respects the same stress unloading and loading the coal permeability stress, $\mathrm{mD}$.

Therefore, we need to carry on the description to the coal rock damage characteristic and establish the relationship between the coal and rock damage and permeability damage. 


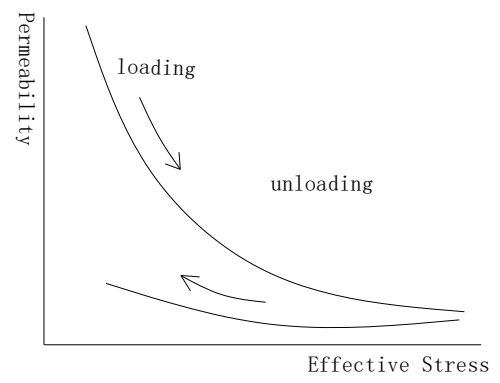

Figure 2. The relation between permeability $\mathrm{k} 2$ and effective stress of plastic model

After unloading, permeability according to the path of evolution, the unloading process of permeability is less than the loading process shows that the permeability, specimen damage, change width of fissure and pore and fracture, elastic and plastic changes happened in coal body, belonging to the elastic-plastic permeability model.

4) The diffusion condition rupture model stressfeature analysis of seepage

Before coal and rock damaged, it has occurred damage national deformation. Deformation of coal body is consists of elastic deformation, damage deformation and failure deformation. If these three can be summed directly and three kinds of deformation of coal and rock mass permeability change can be also summed directly, after the coal fracture permeability can be described as:

$$
k=k_{D}+k_{f}
$$

As the coal produced a large number of new fractures, the volume of fractures and the connectivity of spatial distribution characteristics have major changes and the penetration channel of the fluid changes. Hence, the description key of confining pressure unloading process coal permeability is the description of characteristic of fracture of coal body (space volume and connectivity). After unloading, permeability according to the path of evolution, unloading to the permeability is larger than the loading process of a certain degree of permeability, permeability mutations, showed that the tested fracture, pore part not only changed, and the emergence of new fracture of coal body, rupture, fracture permeability model can be established.

\section{A. Typical permeability evolution curve}

TABLE II. THE STRESS RANGE PERMEABILITY AND CORRESPONDING FORMULA IN DIFFERENT STATES

\begin{tabular}{cccc}
\hline & The stress range & Permeability & The corresponding formula \\
\hline Original stress zone & $\sigma_{0}$ & $\mathrm{k}_{0}$ & $k_{0}$ \\
Compression elastic zone & $\sigma_{0} \sim \sigma_{\mathrm{p}}$ & $\mathrm{k}_{1}$ & $a k_{0} e^{b \sigma}$ \\
Diffusion of plastic zone & $\sigma_{\mathrm{p}} \sim \sigma_{0}$ & $\mathrm{k}_{2}$ & $D_{k} k_{1}$ \\
Diffusion rupture zone & $\sigma_{0} \sim 0$ & $\mathrm{k}_{3}$ & $k_{2}+k_{f}$ \\
\hline
\end{tabular}

The table for the stress range under different conditions, and the corresponding formula of permeability. $\sigma 0$ is the original rock stress value, and $\sigma p$ is stress peak value.

By above knowable: According to the stress partitioning, stress value of original rock stress of primary rock stress zone permeability as the initial permeability is K0. Stress value of original rock stress to the peak stress compaction permeability state of elastic region is K1. Stress diffusion state values for the peak stress to the stress of primary rock plastic zone permeability for K2. Stress diffusion state value of original rock stress to 0 stress work near the surface rupture zone permeability for $\mathrm{k} 3$.

In summary, the permeability formula in different states of the corresponding is as the following:

$$
k=\left\{\begin{array}{l}
k_{0} \\
a e^{b \sigma} \\
D_{k} \times a e^{b \sigma} \\
D_{k} \times a e^{b \sigma}+k_{f}
\end{array}\right.
$$

\section{SimUlation STUDY ON LOWS OF GAS PERMEABILITY}

\section{B. The project background}

The average thickness of coal seam of Henan Coal Mine Group Zhaogu second mine is about $26.5 \mathrm{~m}$, that is below casserole kiln sandstone $45.64 \sim 81.25 \mathrm{~m}$ and above L8 limestone $19.65 \sim 40.24 \mathrm{~m}$. The average thickness of casserole kiln sandstone seam and limestone seam are separately $60.18 \mathrm{~m}$ and $26.5 \mathrm{~m}$.

By the formula (4), obtaining stress permeability curve equation of Zhaogu second mine two-1 coal seam:

$$
\left\{\begin{array}{l}
k_{0}=1.11 \\
k_{1}=5.02 e^{-0.109 \sigma} \\
k_{2}=2.01 e^{-0.109 \sigma}+3 e^{-4.36} \\
k_{3}=2.01 e^{-0.109 \sigma}+3 e^{-4.36}+0.01 \sigma+0.3
\end{array}\right.
$$

Type: K0 for the original stress zone stress-permeability curve; $\mathrm{K} 1$ for the dense elastic zone stress - permeability curve; K2 diffusion plastic zone stress-permeability curve; K3 diffusion rupture zone stress-permeability curve.

\section{The process of numerical simulation of permeability}

The numerical simulation is carried out by FLAC3D and the calculation model, length $200 \mathrm{~m}$, width $50 \mathrm{~m}$, height $120 \mathrm{~m}$, is established based on two-1 coal seam formation condition of the second mine of Zhaogu. The thickness of the two- 1 coal seam is $4 \mathrm{~m}$, below the roof boundary $56 \mathrm{~m}$, above the bottom plate boundary $60 \mathrm{~m}$. Based on Mohr - Kunlun constitutive model, the bottom, left and right boundaries of the model are fixed. The buried depth of the coal seam is $600 \mathrm{~m}$, with the original rock stress reaching $15 \mathrm{MPa}$. Depending on the geological data and the physical and mechanical 
parameters, determine the mechanical parameters of coal and rock mass.

Use FLAC3D to simulate two-1 coal seam's working face four cases, advanced $30 \mathrm{~m}, 50 \mathrm{~m}, 70 \mathrm{~m}$ and $90 \mathrm{~m}$. Before excavating the model, the first is to make the model under the action of gravity of overlying strata achieve the original stress equilibrium state and then use the written FISH function to mine coal seam. Calculate the excavated model till the unbalanced force reaches the set value and then put out the stress nephogram. During the simulation, use FISH function written based on the formula (5) to calculate permeability, distribution and put out the permeability nephogram.

\section{The results of numerical simulation analysis}

Take the working face advancing $30 \mathrm{~m}$ as an example to analyze the simulation results. According to Fig .3 and Fig .4, graph the stress and permeability map descripting the front of the working face. From the figure, in the whole stope: the original rock stress is $15 \mathrm{MPa}$ and the peak stress is $30.3 \mathrm{MPa}$. The initial permeability, the minimum permeability and the maximum permeability is respectively $1.11 \mathrm{mD}, 0.11 \mathrm{mD}$ and $3.5 \mathrm{mD}$. The mining height is $4 \mathrm{~m}$, and the permeability mutation point above gob has an about $32 \mathrm{~m}$ distance. In front of the working face: the original rock stress is $15 \mathrm{MPa}$ (distance from working face $74 \mathrm{~m}$ ), and the peak stress is $36.8 \mathrm{MPa}$. The stress concentration coefficient is 2.5 , and the distance between peak value and the working surface is about $2.8 \mathrm{~m}$. The initial permeability is $1.11 \mathrm{mD}$, and it reduces to the lowest $0.11 \mathrm{mD}$ at the stress peak point (away from the face $2.8 \mathrm{~m}$ ) while it recovers to $0.8 \mathrm{mD}$ at the original rock stress point (away from the face $1.7 \mathrm{~m}$ ) which is slightly less than initial permeability value. The permeability value reaches the maximum, $2.99 \mathrm{mD}$, near the working face.

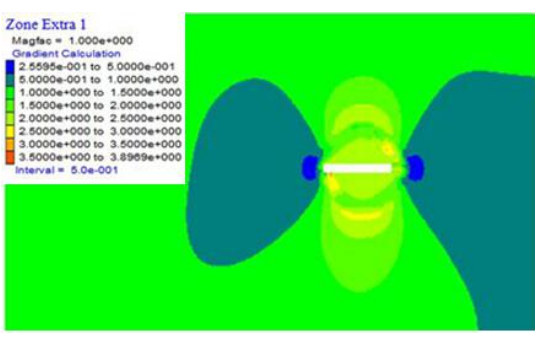

Figure 3. The vertical stress distribution nephogram of 2-1 coal with $30 \mathrm{~m}$ distance
Figure 4. The permeability distribution nephogram of 2-1 coal with $30 \mathrm{~m}$ distance

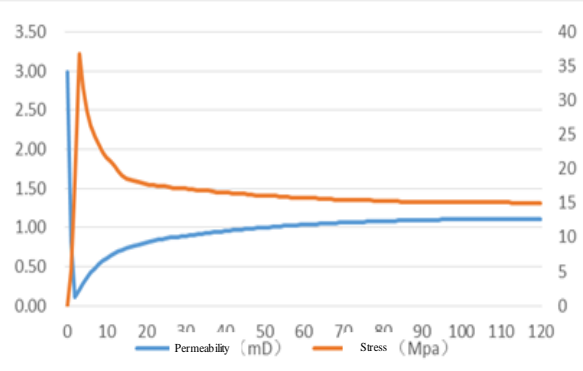

Figure 5. The change in value of stress and permeability before working face with $30 \mathrm{~m}$ distance

Table 3 shows that different distance has an influence on stress and permeability before working face. In front of the working face, with the advancing of working face, the minimum permeability value gradually and significantly decreases which is $3 \mathrm{~m}$ in front of the working face. Permeability coefficient extreme ratio before working face increases exponentially. However, permeability value near working face changes unobviously having a relatively stable value. For the whole stope, the minimum permeability decreases, while the maximum permeability increases. Permeability coefficient extremum ratio increases more obviously than that before working face. At the same time, the distance permeability mutation point above the gob from roof increases.

TABLE III. THE INFLUENCE OF STRESS AND PERMEABILITY BEFORE WORKING FACE CAUSED BY DISTANCE

\begin{tabular}{|c|c|c|c|c|c|c|c|c|c|}
\hline $\mathrm{L}_{0} / \mathrm{m}$ & $f$ & $\mathrm{p}_{\min 0} / \mathrm{mD}$ & $1 / \mathrm{m}$ & $\mathrm{P}_{\max 0} / \mathrm{mD}$ & $\mathrm{r}_{0}$ & $\mathrm{p}_{\min 1} / \mathrm{mD}$ & $\mathrm{P}_{\max 1} / \mathrm{mD}$ & $\mathrm{r}_{1}$ & $1 / m$ \\
\hline 30 & 2.5 & 0.11 & 2.8 & 2.99 & 27.8 & 0.11 & 3.50 & 31.8 & 32 \\
\hline 50 & 3.0 & 0.10 & 3.0 & 2.96 & 29.6 & 0.10 & 4.69 & 46.9 & 36 \\
\hline 70 & 3.5 & 0.03 & 3.2 & 2.98 & 99.3 & 0.03 & 5.86 & 195.3 & 41 \\
\hline 90 & 3.7 & 0.02 & 3.3 & 3.11 & 155.5 & 0.02 & 5.55 & 277.5 & 51 \\
\hline
\end{tabular}

In the table: $\mathrm{L} 0$-the distance of advancing;

f-the stress concentration factor before working face; face pmin0-the minimum permeability before working 
1-the distance between minimum permeability point and working face; face;

pmax0-the maximum permeability before working face;

r0-the permeability extreme ratio before working

pmin1-the minimum permeability in stope;

pmax1-the maximum permeability in stope;

r1-the permeability extreme ratio in stope;

l'-the distance of stress mutation point above the gob from the roof.

The results of numerical simulation show, both in the whole of the stope and the front of the working face, the minimum permeability value appears in the stress concentration point before the working face. The change of minimum permeability value is inversely correlated with the advancing distance. Permeability extreme ratio (the ratio of maximum permeability value and minimum permeability value) increases multiply with working face advancing. In the whole stope, the maximum permeability value appears in the gob roof nearby, increasing with working face advancing. In front of the working face, the maximum permeability value appears in the working face position stalely or with the small amplitude climbing.

\section{CONCLUSIONS}

In this paper, through the theoretical analysis and numerical simulation study of deep mining breaking coal and rock formation characteristics and law of gas flow guide, get the following conclusion:

1) The permeability of the upper surface of coal or rock between now and in the coal and rock fracture penetration level, while essentially permeability coefficient is related to its stress state and stress variation.

2) With the working face advancing, the change of the abutment pressure has a decisive influence on permeability, under different bearing pressure, coal can be divided into the original state, compaction, diffusion state and recovery state and compaction state again, through the theoretical calculated under different stress permeability curve equation.

3) The contour map of tire stope penetration, it is concluded that the biggest and smallest permeability relationship with the working face advance distance and permeability mined-out area at the top of the mutation point location.

\section{REFERENCES}

[1] Qian Minggao, Xu Jialin, Mao Xiexing. Research and application of the green mining technology [J].Technology and Management, 2004(4): 1-4

[2] Luo Haizhu, Liang Yuntao, Lv Guojin. High gassy and inflammable thick coal seam spontaneous combustion prevention and control technology of fully mechanized top coal caving mining $[\mathrm{J}]$. Coal Science and Technology, 2002, 30(9): $1-4$.

[3] Wu Caifang, Zeng Yong, Qin Yong. Present situation and application of research and development of simultaneous extraction of coal and gas [J]. Journal of China University of Mining \& Technology, 2004, 33(2)

[4] Terzaghi K. Theoretical soil mechanics [M]. Wiley, New York, 1943.

[5] Biot M A. General theory of three dimensional consolidation [J].J. Appl. Phys. 1941, 12: 155-164.

[6] Biot M A. General solution of three quation of elasticity and consolidation for aporous material [J].J. Appl. Mech. 1956, 78: 91-96.

[7] Biot M A.Theory of elasticity and consolidation for aporous anisotropic solid [J].J. Appl. Phys. 1954， 26: 182.

[8] Biot M A. Mechanics of deformation and acoustic propagation in porous media [J].J. Appl. Phys. 1962, 33: 1482.

[9] Lubinski A.Theory of elasticity for porous bodies displaying a strong pore structure [J].Proc. 2nd U.S.National Congress of Applied Mechanics.1954: 247-256.

[10] Geertsman J. A remark on the analogy between the mo-elasticity and the elasticity of saturated porous media $[\mathrm{J}]$.J. Mech. Phys. Solids, 1957, 6: 13-16. 